\title{
FIELD PROCEDURES FOR REAL-WORLD MEASUREMENTS OF EMISSIONS FROM DIESEL CONSTRUCTION VEHICLES
}

\author{
William Rasdorf, Ph.D., P.E., F. ASCE, Professor \\ Department of Civil, Construction, and Environmental Engineering \\ North Carolina State University \\ Raleigh, NC 27695-7908 \\ Telephone 919-515-7637, Fax 919-515-7908 \\ Email rasdorf@eos.ncsu.edu \\ Christopher Frey, Ph.D., M. ASCE, Professor \\ Department of Civil, Construction, and Environmental Engineering \\ North Carolina State University \\ Raleigh, NC 27695-7908 \\ Telephone 919-515-1155, Fax 919-515-7908 \\ Email frey@eos.ncsu.edu \\ Phil Lewis, P.E., S.M. ASCE \\ Ph.D. Candidate \\ Department of Civil, Construction, and Environmental Engineering \\ North Carolina State University \\ Raleigh, NC 27695-7908 \\ Telephone 919-269-6144 \\ Emailmplewis@ncsu.edu \\ Kangwook Kim, Ph.D. \\ Graduate Research Assistant \\ Department of Civil, Construction, and Environmental Engineering \\ North Carolina State University \\ Raleigh, NC 27695-7908 \\ Telephone 919-604-3677 \\ Email kkim2@ncsu.edu \\ Shih-Hao Pang, Ph.D. \\ Graduate Research Assistant \\ Department of Civil, Construction, and Environmental Engineering \\ North Carolina State University \\ Raleigh, NC 27695-7908 \\ Telephone 919-523-5824 \\ Email spang@ncsu.edu \\ Saeed Abolhassani \\ Graduate Research Assistant \\ Department of Civil, Construction, and Environmental Engineering \\ North Carolina State University \\ Raleigh, NC 27695-7908 \\ Telephone 919-515-4232 \\ Email abolhasanis@yahoo.com
}

Key Words: air pollution, construction vehicles, diesel engines, emissions, life cycle analysis, pollutants, sustainability 


\title{
FIELD PROCEDURES FOR REAL-WORLD MEASUREMENTS OF EMISSIONS FROM DIESEL CONSTRUCTION VEHICLES*
}

William Rasdorf, H. Christopher Frey, Phil Lewis, Kangwook Kim, Shih-Hao Pang, Saeed Abolhassani

\author{
ABSTRACT \\ INTRODUCTION \\ PREVIOUS WORK \\ VEHICLE EMISSIONS \\ STUDY DESIGN \\ Vehicle Location \\ Vehicle Selection \\ Vehicle Activities \\ Vehicle Data Collection Scheduling \\ REAL-WORLD DATA COLLECTION PROCEDURES \\ Pre-installation of Instrumentation \\ Installation of Instrumentation \\ Emissions Data Collection \\ Visual Data Collection \\ Construction Site and Vehicle Activity Data Collection \\ Vehicle Data Collection \\ Decommissioning of Instrumentation \\ Data Quality Assurance \\ DATA COLLECTION PROBLEMS AND SOLUTIONS \\ Suitable Weather \\ Difficult Operating Conditions \\ Scheduling \\ RESULTS \\ CONCLUSIONS AND RECOMMENDATIONS \\ ADDITIONAL WORK \\ ACKNOWLEDGEMENT \\ REFERENCES
}

*This outline is provided for reviewer convenience. 


\section{ABSTRACT}

Construction vehicles are a source of nonroad mobile air pollutant emissions. Emissions from construction vehicles are typically quantified based on steady-state modal engine dynamometer tests using uninstalled stationary engines. However, these tests do not represent real-world activity. Therefore, there is a need to quantify energy use and air pollutant emissions from construction vehicles based on in-use measurement methods. The purpose of this paper is to outline standard procedures for field data collection for construction vehicles. This methodology is based on second-by-second measurement of in-use activity and air pollutant emissions using a portable emissions measurement system (PEMS). The field data collection methodology includes the development of a study design, installation and use of instrumentation, and field measurements. After the field data collection, the raw data undergo a quality assurance procedure to check for and correct the synchronization between the engine data and emission data. This procedure also identifies missing data and removes incorrect data. The most significant challenges to data collection include suitable weather, difficult operating conditions, and scheduling data collection sessions. Sample real-world data measurement results for a rubber tire loader are presented. The work presented here can be used as a foundational example for conducting other data collection efforts and analysis of construction vehicle emissions. 


\section{INTRODUCTION}

According to the Environmental Protection Agency (EPA), most Americans living in urban areas breathe air that does not meet National Ambient Air Quality Standards (NAAQS) [CFR, 2007] for either ozone or particulate matter. Heavy duty diesel vehicles, including both onroad and nonroad vehicles, emit significant amounts of nitrogen oxides $\left(\mathrm{NO}_{\mathrm{x}}\right)$ which is a precursor to ozone $\left(\mathrm{O}_{3}\right)$ formation and particulate matter $(\mathrm{PM})$. Unlike emissions trends for onroad vehicles, emissions of $\mathrm{NO}_{x}$, carbon monoxide (CO), and hydrocarbons (HC) from nonroad vehicles increased steadily from 1970 to 2006 [EPA, 2007]. In 2005, nonroad diesel construction vehicles were estimated to emit annual U.S. national totals of 657,000 tons of $\mathrm{NO}_{x}$, 1,100,000 tons of CO, 63,000 tons of PM10, and 94,000 tons of SO2 [EPA (1), 2005].

Emissions from nonroad construction vehicles are typically quantified based on steadystate engine dynamometer tests using uninstalled stationary engines. However, these tests do not represent real-world duty cycles. Therefore, there is a need to quantify energy use and emissions from construction vehicles based on in-use measurement methods to assess their true level of contribution.

The proper management of emissions will become increasingly critical to economic growth because effective control measures will be needed in order to come into attainment of the NAAQS. This paper reports on current work [Frey (1) et al, 2007; Frey (2) et al, 2007] related to construction vehicle diesel emissions.

The work presented here recommends a methodology for collecting real-world air pollutant emissions data from nonroad vehicles and equipment. The methodology consists of second-by-second measurement of in-use activity and emissions using a Portable Emissions Monitoring System (PEMS). This methodology has been used to measure the in-use activity and 
pollutant emissions of backhoes, bulldozers, excavators, generators, motor graders, off-highway trucks, rubber tire loaders, track loaders, and skid-steer loaders.

This work identifies the critical data items that ultimately allow for a detailed assessment and inventory quantification. The identification of and solutions for field measurement problems are also described. Overall, this paper addresses the following items:

1. Characterization of construction vehicle emissions

2. Influence of construction tasks and vehicle activity modes on emissions

3. Procedures for real-world, in-use emissions data collection

4. Problems and solutions associated with real-world emissions data collection

5. Typical results of real-world emissions data collection

The results from the application of this methodology will improve the characterization of in-use activity and pollutant emissions of these vehicles, which can further support the development of highly accurate air pollutant emissions inventories and improved approaches to air quality management. The data collected can be used in additional research.

The results can be used by the academic community and field practitioners. The data collection methodology presented here provides a framework for real-world emissions data collection from nonroad diesel vehicles that can be used by other researchers in various analyses. Field practitioners, such as engine manufacturers, vehicle owners, fleet managers, contractors, environmental engineers, and air quality officials have a vested interest in knowing the impact of emissions from nonroad diesel engines on air quality and the environment.

\section{PREVIOUS WORK}

Numerous studies have examined infrastructure life cycle assessments and impacts of air

pollution on the environment. Junnila and Horvath [2003] suggest that the construction and 
demolition processes for office buildings have a relatively insignificant impact on the environment when viewed over the entire life of the building. Matthews et al [2001] recommend examining the manufacturing processes that produce construction equipment and materials. Bilec et al [2006] and Guggemos and Horvath [2005] also advocate the examination and quantification of environmental impacts for all phases of the life cycle for constructed facilities.

While Matthews et al focuses on the manufacture of construction equipment, Guggemos and Horvath focus on the energy use and emissions related to the manufacture of construction materials for framed buildings, such as concrete and steel. Zapata and Gambatese [2005] also focus on the energy consumption and environmental impact of construction materials, including asphalt and reinforced concrete pavements. Similar to Mathews et al and Guggemos and Horvath, Zapata and Gambatese conclude that the most energy is consumed in the manufacture of steel, concrete, and asphalt.

This paper focuses on the construction phase of the life cycle and the air pollutants emitted from construction vehicles and equipment. A methodology is presented for real-world emissions data collection that can be used to support other environmental impact studies. This paper is similar to the work by Glaser and Tolman [2008] which describes performance modeling approaches, data collection, and refining data for decision support information.

\section{VEHICLE EMISSIONS}

As fuel is consumed by a vehicle's engine, tailpipe air pollutant emissions are produced. For diesel construction vehicles, the pollutants of primary concern are $\mathrm{NO}_{\mathrm{x}}, \mathrm{HC}, \mathrm{CO}$, and PM. There are factors that influence the quantities of emissions that are produced, such as the task that the vehicle is performing and the various vehicle and engine activities that are occurring while the task is being performed. Figure 1 illustrates this process for a rubber tire loader. 
Figure 1 shows that fuel is consumed by the rubber tire loader while it completes the task of loading dirt into a dump truck. To complete this task, the rubber tire loader must perform the duty cycle components of scooping dirt from a pile with its bucket, traveling with its bucket loaded to the truck, dumping the dirt into the truck, and returning to the pile with its bucket empty. The rubber tire loader must repeat this duty cycle many times until the desired amount of dirt has been moved.

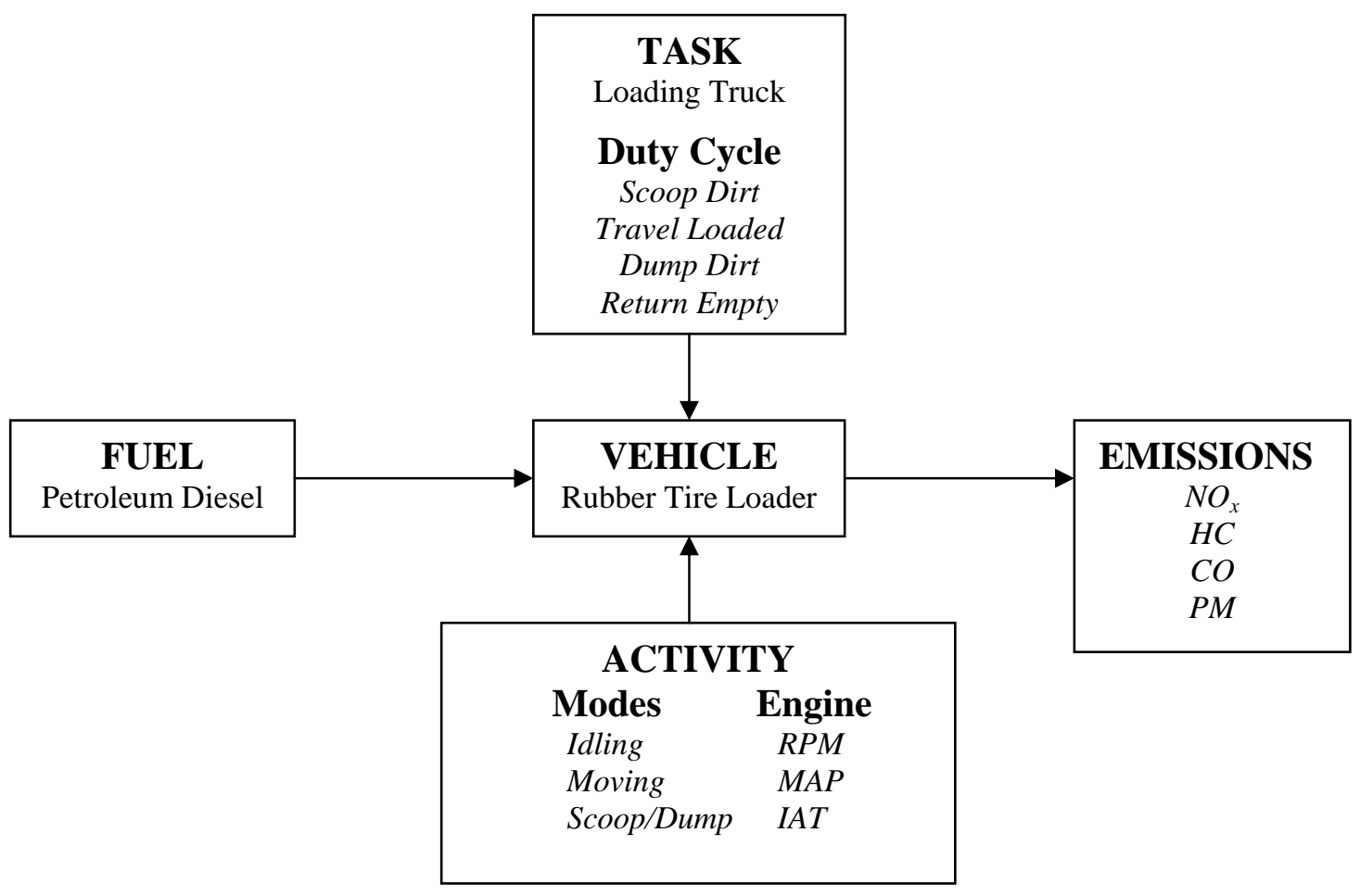

Figure 1. Production of Construction Vehicle Emissions

While this duty cycle is being performed by the rubber tire loader, there are specific vehicle activities and engine parameters that are measurable. These vehicle activities, known as activity modes, include idling, moving with the bucket empty, and moving with the bucket loaded which begins with scooping the dirt and ends with dumping the dirt. The duration of each activity mode is measured in seconds. As the rubber tire loader performs these activities, 
specific engine parameters are monitored. These parameters typically include revolutions per minute (RPM), manifold absolute pressure (MAP), and intake air temperature (IAT). For any task with a particular duty cycle, these activity modes and engine parameters can be measured to determine their relationship to emissions.

This relationship is expressed in terms of an emission factor. An emission factor is the rate at which pollutants are emitted into the atmosphere. Emission factors may be based on mass per time or mass per fuel used. For example, emission rates may be expressed as the mass of pollutant in grams that is emitted per unit of time in seconds $(\mathrm{g} / \mathrm{s})$; likewise, emission rates may be expressed as the mass of pollutant in grams that is emitted per unit of fuel consumed in gallons (g/gal). Based on these fundamental emissions factors, other relationships may be determined, such as tons of pollutant emitted per year or grams of pollutant emitted per unit of vehicle production.

With respect to Figure 1, a major concern is determining what is known and what is unknown. If emissions and time are both measured, then emissions can be related directly to time (g/s). Emissions can also be related to fuel (g/gal), based on a carbon balance. If the fuel flow rate or the exhaust flow rate is measured, then emissions can be estimated on a mass per time basis $(\mathrm{g} / \mathrm{s})$. If vehicle activity is measured, then emissions can be related to activity modes and engine parameters. Therefore, trends in emissions over time can be correlated with engine performance. Furthermore, if the vehicle duty cycle is monitored, then emissions can be related to the task.

Armed with this knowledge, vehicle owners can begin to examine their fleets with regard to emissions and develop strategies for emissions reductions. So far, the burden of reducing emissions has been borne by engine manufacturers who have had to meet ever more stringent 
regulations [EPA (2), 2005; CARB 2004]. That burden could one day be expanded to more direct involvement of vehicle owners, such as requirements for replacing older vehicles with newer ones or emissions control retrofits for existing diesel engines. For example, many construction vehicle owners in California are already retrofitting older vehicles with newer engines in anticipation of approval of a draft rule by the California Air Resources Board (CARB) that would call for a ban on vehicles and equipment that is more than 10 years old [ENR, 2006]. Thus, quantification and characterization of emissions from diesel construction vehicles is necessary.

\section{STUDY DESIGN}

The key elements of the study design for real-world emissions data collection included the following:

- Vehicle Selection

- Vehicle Activity

- Vehicle Location

- Vehicle Data Collection Scheduling

\section{Vehicle Selection}

The types of construction vehicles selected for data collection were prioritized based on analyses using the EPA NONROAD model [EPA (1), 2005]. NONROAD was used to rank construction vehicles based on their respective contribution of $\mathrm{NO}_{\mathrm{x}}, \mathrm{CO}$, and $\mathrm{PM}_{10}$. Essentially, the vehicles that produced the highest quantities of these emissions, as determined by NONROAD, were selected for the study. The selected vehicles and equipment included: 
- Backhoes

- Bulldozers

- Excavators

- Generators

- Motor Graders

- Off-Highway Trucks

- Rubber Tire Loaders

- Track Loaders

- Skid-Steer Loaders

The selected vehicles and equipment are estimated to contribute over 70 percent of all $\mathrm{NO}_{\mathrm{x}}, \mathrm{CO}$, and $\mathrm{PM}_{10}$ from construction vehicles and equipment in the United States. Table 1 summarizes the data that were estimated using the NONROAD ranking of these vehicles and equipment based on their contribution of $\mathrm{NO}_{\mathrm{x}}, \mathrm{CO}$, and $\mathrm{PM}_{10}$. For example, rubber tire loaders contribute $14.5 \%$ of all $\mathrm{NO}_{\mathrm{x}}$ produced by construction vehicles and equipment, which makes them the most significant contributor of $\mathrm{NO}_{\mathrm{x}}$. However, they are the number three contributor of $\mathrm{CO}$ and $\mathrm{PM}_{10}$, producing $11.5 \%$ and $11.2 \%$ of these emissions respectively.

\section{Vehicle Activity}

The type of task and related duty cycle being performed by a vehicle can influence the engine load of the vehicle. For example, a rubber tire loader moving with its bucket loaded imposes a higher load on the engine than a rubber tire loader moving with the bucket empty. Typically, emissions from the vehicle increase as the engine load of the vehicle increases. Engine load was monitored by measuring MAP. 
Table 1. Comparison of Contribution and National Ranking of $\mathrm{NO}_{\mathrm{x}}, \mathrm{CO}$, and $\mathrm{PM}_{10}$ for Selected Vehicles and Equipment

\begin{tabular}{|c|c|c|c|c|c|c|}
\hline \multirow[b]{2}{*}{ Vehicle } & \multicolumn{2}{|c|}{$\mathbf{N O}_{\mathrm{x}}$} & \multicolumn{2}{|c|}{$\mathrm{CO}$} & \multicolumn{2}{|c|}{$\mathbf{P M}_{10}$} \\
\hline & $\begin{array}{c}\text { Contribution } \\
(\%)\end{array}$ & $\begin{array}{l}\text { National } \\
\text { Ranking } \\
\end{array}$ & $\begin{array}{c}\text { Contribution } \\
(\%)\end{array}$ & $\begin{array}{l}\text { National } \\
\text { Ranking } \\
\end{array}$ & $\begin{array}{c}\text { Contribution } \\
(\%)\end{array}$ & $\begin{array}{l}\text { National } \\
\text { Ranking } \\
\end{array}$ \\
\hline Front-End Loaders & 14.5 & 1 & 11.5 & 3 & 11.2 & 3 \\
\hline Bulldozers/Track Loaders & 12.5 & 2 & 9.3 & 4 & 9.1 & 4 \\
\hline Excavators & 11.4 & 3 & 7.4 & 5 & 8.6 & 5 \\
\hline Off-Highway Trucks & 11.0 & 4 & 7.3 & 6 & 6.6 & 6 \\
\hline Backhoes & 9.2 & 5 & 16.0 & 1 & 15.1 & 1 \\
\hline Skid-Steer Loaders & 6.2 & 6 & 14.5 & 2 & 13.6 & 2 \\
\hline Generators & 4.7 & 7 & 5.1 & 7 & 6.0 & 7 \\
\hline Motor Graders & 2.9 & 12 & 1.7 & 14 & 2.1 & 13 \\
\hline & 72.4 & & 72.8 & & 72.3 & \\
\hline
\end{tabular}

Activity modes were observed to relate the engine load to the activity that was being performed. Similar to duty cycle components, activity modes are a set of specific actions that a vehicle performs to accomplish a specific task. However, the difference is that activity modes were observed for the specific purpose of determining how particular actions of the vehicle affect the emissions of the vehicle. Therefore, idling was an observed activity mode but it is not usually considered to be a duty cycle component. Furthermore, activity modes are based on the timeline of each specific activity of the vehicle rather than on the overall task to be completed. The following activity modes for a rubber tire loader were observed:

Idling

The engine is on but the rubber tire loader is not moving and is not performing work.

Moving

The engine is on and the rubber tire loader is moving in either the forward or the reverse direction to another location while the bucket is unloaded.

Scoop/Dump

The engine is on and the rubber tire loader is performing work, beginning with scooping material with the bucket, moving to another location while loaded, and ending with dumping the material. Once the bucket is empty and the front-end loader begins to move, the activity mode returns to Moving. 


\section{Vehicle Location}

The primary study area was on or near the campus of North Carolina State University (NCSU). NCSU has undergone significant construction activities, and there have been numerous construction sites on campus. Additionally, there were many construction projects in the area surrounding NCSU which had the selected types of construction vehicles available for monitoring. Whereas some vehicle owners did not wish to participate in the study, many were willing to cooperate.

\section{Vehicle Data Collection Scheduling}

Prior to data collection, permission to monitor the vehicle was obtained from the vehicle owner, the project supervisor, and the vehicle operator. Permission was also obtained to interact with the operator and the vehicle during the data collection process. These individuals were assured of the following:

- The data collection process would not interfere with nor interrupt the productivity of the vehicle.

- The PEMS used to collect emissions and engine data from the construction vehicle would neither temporarily nor permanently affect engine operation.

- The research team would maintain a safe distance from all construction activities.

Scheduling vehicle data collection with the owners took varying amounts of time. For instance, some owners were very responsive and would provide an answer within 48 hours. Some owners were altogether non-responsive, therefore other owners had to be contacted. When an owner agreed to participate in the study, data collection could be scheduled for the next opportunity that the particular vehicle would be used. 


\section{REAL-WORLD DATA COLLECTION PROCEDURES}

The real-world data collection procedures included eight distinguishable components. The research team, usually consisting of two or three individuals, performed the following data collection procedures:

1. Pre-Installation of Instrumentation

2. Installation of Instrumentation

3. Emissions Data Collection

4. Visual Data Collection

5. Construction Site and Vehicle Activity Data Collection

6. Vehicle Data Collection

7. Decommissioning of Instrumentation

8. Data Quality Assurance

\section{Pre-Installation of Instrumentation}

The instrumentation used for emissions and engine data collection was complex and was installed in two phases: pre-installation and installation. Pre-installation occurred the day before the data was collected from the vehicle. The purpose of pre-installation was to perform the following:

- Install the safety cage on the vehicle. The safety cage securely held the PEMS during the data collection process and helped to protect the PEMS from damage.

- Install the PEMS sensor array on the engine. The sensor array was used to collect engine data such as IAT, MAP, and RPM.

- Install the external battery on the vehicle. A separate battery was provided to power the PEMS so the vehicle's battery was not required to provide power to the PEMS. 
- Install the global positioning system (GPS) on the vehicle. Although the GPS data was not used in this research, it was collected for future use.

The pre-installation process was completed the day before data collection occurred. This process typically took two individuals approximately two hours and forty minutes to complete. Since each step took a significant amount of time to complete, they could not be performed during the morning that the vehicle was placed into service. Furthermore, additional steps related to the installation procedure needed to be completed during the morning of data collection.

\section{Installation of Instrumentation}

Due to weather and security concerns, it was not desirable to completely install the PEMS and leave it on the vehicle overnight. Therefore, the day after pre-installation occurred, the research team typically arrived at the construction site approximately two hours before the vehicle began operation to complete the installation of the PEMS. The following were performed to complete the final installation process:

- Place the PEMS in the safety cage on the vehicle

- Connect the emissions sample hoses from the vehicle to the PEMS

- Connect the sensor array cables from the vehicle's engine to the PEMS

- Connect the cables from the external battery to the PEMS

- Connect the cable from the GPS to the PEMS

- Start the PEMS and allow it to warm up for 45 minutes per the manufacturer's specifications

The main unit of the PEMS was typically mounted on the roof of the vehicle in a safety cage so it would not interfere with the operation of the vehicle. Foam padding was placed inside 
the safety cage to minimize the transmittance of vibration from the vehicle to the PEMS. A thin, cloth dust cover was placed over the safety cage to prevent dust from entering the main unit of the PEMS. A reflective cover was placed on top of the safety cage to help prevent the PEMS from overheating from exposure to the sun.

While the PEMS was warming up, the research team would discuss the work schedule with the vehicle operator. A suitable location for the research team to observe the vehicle activity was agreed upon. The vehicle operator and the research team also had to agree on a schedule for the research team to periodically check the PEMS, which was usually in 30 minute intervals.

\section{Emissions Data Collection}

When the PEMS had completed warm-up and the vehicle began operation, the research team was able to begin collecting emissions data from the vehicle as it performed real-world construction activities. This was done through the combined use of the PEMS and a separate laptop computer. The PEMS was used to collect emissions, engine, and location data and the laptop computer was used to collect vehicle activity data.

The PEMS that was used for data collection was the Montana system manufactured by CATI, Inc. [CATI, 2003]. Via a sample probe inserted into the tailpipe, the Montana measured second-by-second mass emissions of nitric oxide (NO), HC, CO, and PM. The Montana also measured carbon dioxide $\left(\mathrm{CO}_{2}\right)$.

The Montana used non-dispersive infrared (NDIR) detection to measure $\mathrm{CO}_{2}, \mathrm{CO}$, and HC, and used electrochemical cells to measure NO and oxygen $\left(\mathrm{O}_{2}\right)$. A detailed assessment of the precision and accuracy of the PEMS is reported by Battelle [2003]. The Montana produced accurate data for $\mathrm{NO}, \mathrm{CO}$, and $\mathrm{CO}_{2}$. The $\mathrm{HC}$ data tend to be based low because NDIR responds 
more accurately to straight chain HC than to aromatic compounds [Stephens and Cadle, 1991]. Therefore, the reported emission factors may be low by a factor of two.

PM measurements were obtained by a light scattering laser photometer detection method. The PM detection method is analogous to opacity, which refers to the degree to which light is blocked. The PM measurements should not be used for characterization of the absolute magnitude of such emissions. However, they are useful for relative comparisons of PM emission rates. Previous comparisons of the opacity-based measurements to other PM data imply that absolute values inferred from the opacity-based measurements could be low by an order of magnitude.

There are two ways that the Montana collects engine parameter data. One is through the use of an electronic control unit (ECU) that is part of the engine itself. The ECU collects and reports engine parameters and diagnostic data. An engine scanner may be connected to the ECU to record engine data from the vehicle. The Montana is capable of being connected to the scanner and obtaining the engine data directly. The ECU is typically available on highway vehicles but is not currently available on nonroad vehicles, thus it was not used to collect engine data. The second way that the Montana can collect engine data is through a sensor array that connects to the vehicle's engine to obtain engine data. The variables that are measured are IAT, MAP, and RPM. The engine data for this work was collected by using the sensor array.

The Montana is also equipped to record vehicle location data from a GPS. This allows the vehicle to be tracked in real time, thus providing data on the position, path, and speed of the vehicle. This data may also be useful for other research in construction operations analysis, such as time studies for construction vehicle duty cycles (Hildreth et al, 2005). 
A laptop computer was used to collect and record activity modes for each vehicle. Although the laptop computer was not directly connected to the Montana, it was coordinated with it via the laptop computer's internal clock. Therefore, the activity modes of the vehicle were directly linked to its air pollutant emissions. The clock of the laptop computer was synchronized with the clock of the Montana to enable a second-by-second analysis of the emissions by activity mode.

During data collection, the research team followed the vehicle at a safe distance without interfering with the vehicle's operation. The objective was to record modal activity data without interrupting the production of the vehicle. Recording activity mode duration was accomplished by using the numeric keypad of the laptop computer. Each activity mode of the vehicle was classified by a keypad number. For example, the activity modes and their corresponding number for a rubber tire loader were:

1. Scoop/Dump

2. Moving

3. Idling

Each time the rubber tire loader began one of these activity modes, the corresponding number was pressed on the numeric keypad. For example, when the rubber tire loader began to idle, the 3 key was pressed on the keypad; when the rubber tire loader began to move with the bucket empty, the 2 key was pressed on the keypad. Since the time was recorded for each keystroke, the duration of each recorded activity mode could be determined. Both the Montana and the laptop computer were synchronized to the current time before data collection began. Furthermore, the emissions data from the Montana was linked to the activity mode data from the laptop computer to provide a detailed timeline of emissions and activity for the vehicle. 


\section{Visual Data Collection}

A video camera was used to record the activity pattern of the vehicle at the construction site. The video camera was set up in a location that enabled it to observe all activities of the vehicle, but without interfering with the work of the vehicle. The video camera recorded the following information:

- The task and duty cycles being performed by the vehicle at the site

- The typical activity modes of the vehicle

- The site characteristics, including terrain and weather

Enough video data was obtained to document the typical work activities and patterns being measured and the activity modes of the vehicle. This was usually done with approximately 15 to 30 minutes of video. It was not necessary to record everything that the vehicle did, but only those activities that represented the typical activity modes for which data was collected.

In addition, a general panoramic view of the construction site was recorded to show the working environment of the vehicle. Essentially, the video enabled the data collection team to gather a form of visual data regarding the site, the vehicle, and the work being performed by the vehicle. This was done to allow a visual analysis in case anomalies arose in the data that might be explained by an unusual or unanticipated duty cycle or operator activity.

\section{Construction Site and Vehicle Activity Data Collection}

A necessary part of the overall data collection process was to assess the field conditions at the construction site where the vehicle was working and to record the nature of the work. There were three types of data that were collected: General, Work Activity, and Modal Description. General data included basic information such as the project name and location, the date and time of the data collection session, and the weather, terrain and type of soil encountered 
at the project site. Work Activity information included a description of the task and duty cycles being performed by the vehicle as well as any quantities and units of production that could be measured. Modal Description information included a listing and description of the vehicle activity modes that were observed. All of this data was collected on paper worksheets in the field and then transferred to an electronic spreadsheet for archiving.

This type of information was important for comparisons of emissions data among vehicle activity. For example, the emissions data for a rubber tire loader that was being used to move dirt at a particular location could be compared to the emissions data for a similar rubber tire loader that was being used to move rock at another location. Assessing and recording the field conditions and vehicle activity enabled the analysis of emissions data with respect to tasks and activity modes for each vehicle.

\section{$\underline{\text { Vehicle Data Collection }}$}

Another necessary part of the overall data collection process was to collect and record information related to the specific vehicle that was being tested. This information included data for the identification, chassis, engine, and owner of the vehicle. Identification data included the owner's identification number for the vehicle as well as the manufacturer's Vehicle Identification Number (VIN). Chassis data included information about the vehicle itself, such as the manufacturer, model number, model year, and gross vehicle weight (GVW). Engine data included information about the vehicle's engine, such as the manufacturer, model number, model year, aspiration, displacement, number of cylinders, horsepower, and hours of use. Owner data included contact information for the party responsible for the vehicle, such as name and telephone numbers. All of this data was recorded on paper worksheets in the field and transferred to an electronic spreadsheet for archiving. 
This type of information was important for comparisons of emissions data based on the vehicle's engine and the vehicle type. For example, emissions data for five rubber tire loaders could be compared to determine how emissions changed as the horsepower rating changed. Also, emissions data from rubber tire loaders could be compared and contrasted to emissions data for track loaders to evaluate emissions based on the type of vehicle that is being used.

\section{Decommissioning of Instrumentation}

When the data collection process had been completed, the research team removed the instrumentation from the vehicle. This decommissioning process typically took approximately thirty minutes to complete, after which all of the equipment was returned to the laboratory to be cleaned and prepared for the next data collection session.

When a data collection session had ended, all of the data that had been collected were saved. The data were backed up on a compact disc (CD), as well as another computer. The video data were saved on a digital video disc (DVD) and also on another computer. The emissions data and engine parameter data were later reviewed and screened for quality assurance.

\section{Data Quality Assurance}

Data screening and quality assurance was the procedure for reviewing data collected in the field, determining whether any errors or problems existed in the data, correcting such errors or problems where possible, and removing invalid data if the errors or problems could not be corrected. The goal of data quality assurance was to produce a database that contained valid data. A detailed description of the data quality assurance procedures is provided in Frey et al (1) [2007]. 
The quality assurance process consisted of 19 steps, 16 of which were performed automatically by computer macros and three of which were performed manually. One of the primary concerns was to check the synchronization of data streams from the sensor array and exhaust gas analyzers within the PEMS, as well as communication between the sensor array and the PEMS. Typical data errors included unusual IAT, MAP, and RPM values and negative emissions values. When such data were found, they were corrected and allowed to remain in the dataset. If they could not be corrected, these data were removed from the dataset. On average, approximately seven percent of the raw second-by-second data that was collected in the field were excluded from the final processed data that were used for analysis.

\section{DATA COLLECTION PROBLEMS AND SOLUTIONS}

Real-world emissions data collection from nonroad vehicles occurs in the challenging and difficult environment of a construction work site. Therefore, several problems were encountered with regard to the collection of emissions, vehicle, and site data. These problems included:

- Suitable weather

- Difficult operating conditions

- Scheduling

\section{Suitable Weather}

The Montana system is a sensitive electro-mechanical instrument that was designed for use in a controlled and moderate environment; it is not a "ruggedized" instrument. Thus, construction sites posed significant challenges when using the Montana, particularly with regard to temperature and moisture. 
Data collection could not occur during a rain or snow event because the Montana was typically installed on an external surface of the vehicle. However, it could be used under these conditions if it was installed in a space conditioned cab, such as an off-road truck. Additionally, if the temperature dropped below freezing $\left(32^{\circ} \mathrm{F}\right)$, data collection could not occur because moisture in the sample line would freeze. Likewise, if the ambient temperature exceeded $90^{\circ} \mathrm{F}$ and if the Montana was installed externally on the vehicle, data collection could not occur because the Montana is susceptible to overheating and would shut down at high temperatures. Therefore, the research team only collected data for nonroad vehicles on non-precipitation days and only when the temperature was between $32^{\circ} \mathrm{F}$ and $90^{\circ} \mathrm{F}$. The actual range of temperatures for the collected data was $35^{\circ} \mathrm{F}$ to $87^{\circ} \mathrm{F}$.

\section{Difficult Operating Conditions}

The Montana is sensitive to vibration transmitted from the vehicle as well as to dust and mud that are typically found on construction sites. Vibration, dust, and mud were frequently responsible for causing the Montana to malfunction. When these demanding conditions caused a malfunction, it was necessary to return the instrument to the manufacturer for repairs. These repairs required between several weeks and several months to complete, resulting in critical and substantial lost time for data collection.

These problems were solved by various methods. For instance, to minimize the effects of vibration on the Montana, three layers of one inch foam padding were placed between the surface of the Montana system and the surface of the vehicle. To prevent dust from entering the Montana, a dust cover was fabricated using a fine mesh material. The cover acted as a filter that prevented dust from entering the Montana but allowed adequate air flow around it. A reflective sun cover was placed over the Montana to prevent it from overheating due to sun exposure. The 
research team checked the Montana at approximately 30 minute intervals during the data collection process to ensure that it was still functioning properly. Furthermore, the Montana was cleaned internally between data collection sessions.

\section{Scheduling}

For data collection to occur, it was necessary to find vehicle owners that were willing to allow their vehicles to be tested. This was challenging because the vehicle owner had to be convinced that the installation of the Montana would not adversely affect the operation of the engine. Also, the owner had to be convinced that the data collection process would not interfere with the productivity of their operations.

When the owners allowed their vehicles to be tested, data collection had to be scheduled to accommodate the production schedule. This was difficult because owners would sometimes change their work schedule without notifying the research team ahead of time and a data collection day would be lost. Also, the data collection schedule sometimes changed due to the weather as well as to other unforeseeable events, such as a vehicle malfunction or operator absence. Ultimately, the data collection schedule was dependent upon a combination of the construction schedule, vehicle availability, and site conditions.

\section{RESULTS}

The real-world data collection procedures presented here yielded results for 39 total vehicles. These vehicles included eight backhoes, six bulldozers, three excavators, four generators, six motor graders, three off-road trucks, five rubber tire loaders, three track loaders, and one skid-steer loader. Furthermore, five backhoes, four rubber tire loaders, and six motor graders were tested two times each - once while the vehicle was using petroleum diesel fuel and once while the vehicle was using B20 biodiesel fuel. 
To illustrate the types of insights gained from the emissions data collected using the described real-world data collection procedures, an example is provided for a rubber tire loader that was tested using petroleum diesel and B20 biodiesel. The emissions data that were collected were analyzed on a second-by-second basis for each observed activity mode and for each type of fuel. Figure 2 shows a comparison of $\mathrm{NO}$ (reported as equivalent $\mathrm{NO}_{2}$ ), $\mathrm{HC}$, $\mathrm{CO}$, and $\mathrm{PM}$ for a rubber tire loader based on activity modes and fuel type.

With respect to activity modes, Figure 2 shows that this rubber tire loader emits more NO, HC, and PM while engaged in the Moving and Scoop/Dump activity modes than while engaged in the Idling activity mode, especially when using petroleum diesel; CO emissions remain almost constant regardless of the activity mode and the fuel type. With respect to fuel type, Figure 2 shows that this rubber tire loader emits more HC and PM while using petroleum diesel instead of B20 biodiesel; NO and CO emissions are almost the same for both types of fuel for this rubber tire loader.

Another type of analysis that was performed with real-world emissions measurements was a task-based analysis. This type of analysis compared emissions based on the type of task that was being performed by a specific type of vehicle. For example, typical tasks that were analyzed for rubber tire loaders included Rock Handling, Soil Handling, and Loading Trucks. Table 2 shows a comparison of average emission rates for four rubber tire loaders that performed these three types of tasks. Furthermore, comparisons were made for these vehicles while they used petroleum diesel and also while they used B20 biodiesel.

With respect to task-based emission rates, Table 2 shows that the average emission factor for four rubber tire loaders performing a Rock Handling task is higher than the average emission factors for a Soil Handling task and a Loading Trucks task. Furthermore, the average emission 

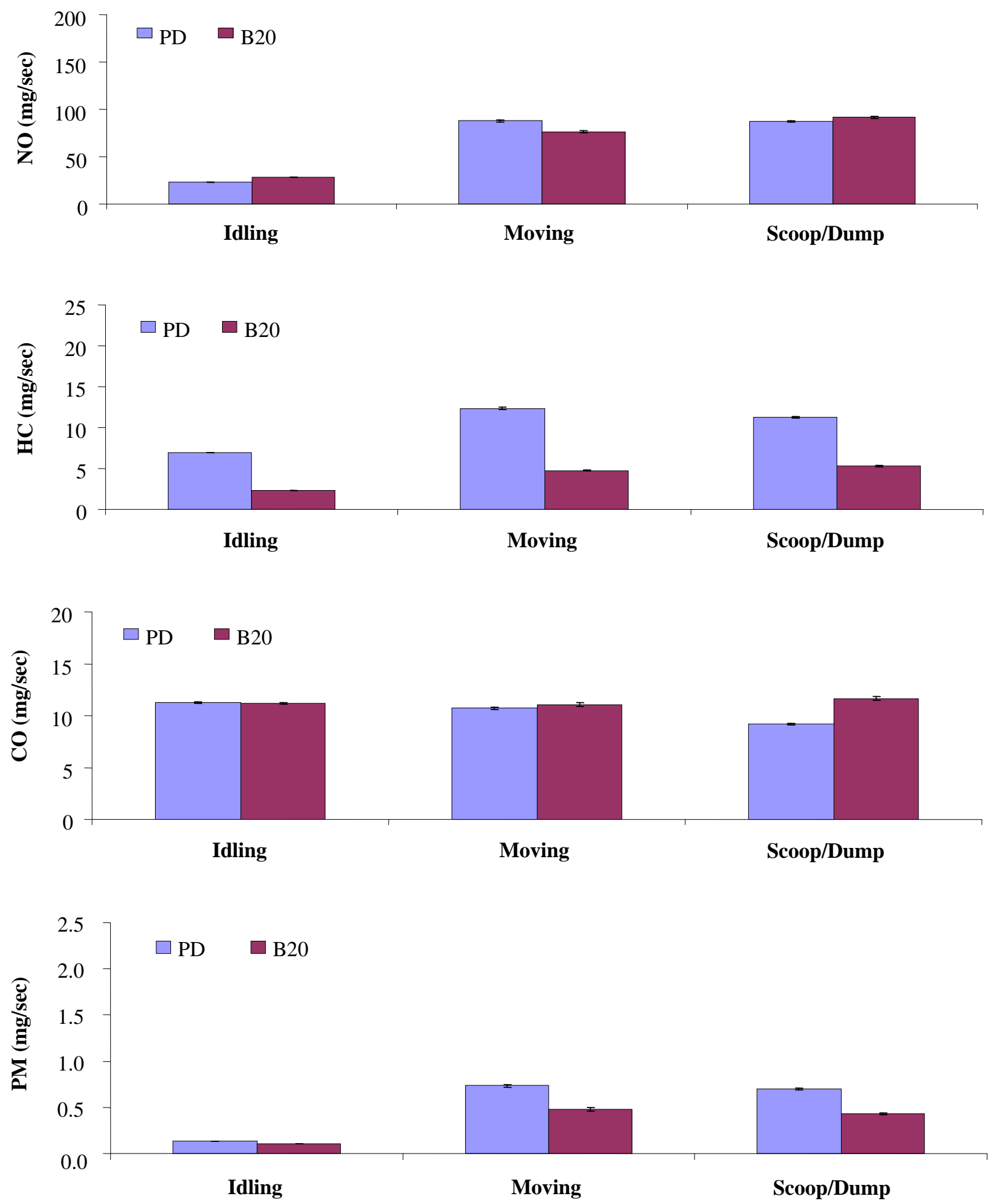

Figure 2. Comparison of Emissions for Rubber Tire Loader Number 1 Based on Activity Modes and Fuel Type [Frey (1) et al, 2007] 
rates of $\mathrm{PM}, \mathrm{HC}$, and $\mathrm{CO}$ are higher for these tasks based on petroleum diesel than for B20 biodiesel; the average emission rates are essentially the same for HC based on fuel type.

Table 2. Comparison of Emissions for Rubber Tire Loaders Based on Task and Fuel Type [Frey (1) et al, 2007]

\begin{tabular}{|c|c|c|c|c|c|c|c|}
\hline \multirow{2}{*}{ Pollutant } & \multirow{2}{*}{ Vehicle } & \multicolumn{3}{|c|}{ B20 Biodiesel } & \multicolumn{3}{|c|}{ Petroleum Diesel } \\
\hline & & $\mathbf{R H}^{\mathbf{a}}$ & SH $^{\mathbf{b}}$ & $\mathbf{L T}^{\mathrm{c}}$ & $\mathbf{R H}^{\mathbf{a}}$ & $\mathbf{S H}^{\mathbf{b}}$ & $\mathbf{L T}^{\mathrm{c}}$ \\
\hline \multirow{5}{*}{$\begin{array}{c}\text { NO } \\
\text { (mg/sec) }\end{array}$} & FL1 & 76 & 72 & 70 & 73 & 69 & 65 \\
\hline & FL2 & 67 & 64 & 58 & 75 & 69 & 67 \\
\hline & FL3 & 111 & 105 & 102 & 109 & 102 & 96 \\
\hline & FL4 & 56 & 54 & 51 & 59 & 55 & 53 \\
\hline & Average & 78 & 74 & 70 & 79 & 74 & 70 \\
\hline \multirow{5}{*}{$\begin{array}{c}\text { PM } \\
\text { (mg/sec) }\end{array}$} & FL1 & 0.45 & 0.42 & 0.41 & 0.68 & 0.63 & 0.63 \\
\hline & FL2 & 0.24 & 0.22 & 0.22 & 0.29 & 0.27 & 0.26 \\
\hline & FL3 & 0.64 & 0.60 & 0.59 & 0.78 & 0.71 & 0.73 \\
\hline & FL4 & 0.36 & 0.32 & 0.34 & 0.40 & 0.37 & 0.37 \\
\hline & Average & 0.42 & 0.39 & 0.39 & 0.54 & 0.50 & 0.50 \\
\hline \multirow{5}{*}{$\begin{array}{c}\text { HC } \\
\text { (mg/sec) }\end{array}$} & FL1 & 5.0 & 4.7 & 4.7 & 11 & 11 & 11 \\
\hline & FL2 & 4.5 & 4.2 & 4.3 & 9.1 & 8.7 & 8.6 \\
\hline & FL3 & 8.0 & 7.6 & 7.7 & 11 & 10 & 9.6 \\
\hline & FL4 & 3.0 & 2.9 & 2.8 & 3.4 & 3.2 & 3.1 \\
\hline & Average & 5.1 & 4.9 & 4.9 & 8.6 & 8.2 & 8.1 \\
\hline \multirow{5}{*}{$\begin{array}{c}\mathrm{CO} \\
(\mathrm{mg} / \mathrm{sec})\end{array}$} & FL1 & 8.6 & 8.2 & 8.8 & 9.5 & 9.1 & 10 \\
\hline & FL2 & 5.4 & 5.2 & 5.3 & 7.1 & 6.9 & 7.1 \\
\hline & FL3 & 7.3 & 6.8 & 6.8 & 13 & 12 & 12 \\
\hline & FL4 & 5.6 & 5.2 & 5.0 & 6.7 & 6.2 & 6.3 \\
\hline & Average & 6.7 & 6.4 & 6.5 & 9.1 & 8.6 & 8.9 \\
\hline
\end{tabular}

${ }^{\mathrm{a}}$ Rock Handling Task

${ }^{\mathrm{b}}$ Soil Handling Task

${ }^{\mathrm{c}}$ Loading Tuck Task

Figure 2 and Table 2 show the types of comparisons that were made using real-world emissions data. Analyses based on activity modes and construction tasks reveal if there are consistent trends in the relationship between emissions and vehicle activity. These types of analyses were conducted for all 39 vehicles as they used petroleum diesel. For the 15 vehicles that were tested using both petroleum diesel and B20 biodiesel, the effects of fuel type on emissions were included in the analyses. In addition to the mass per time emission factors 
shown in Figure 2 and Table 2, the emission factors were also converted to and compared as mass per fuel used emission factors.

\section{CONCLUSIONS \& RECOMMENDATIONS}

Data are required to effectively understand the emissions problem and to determine its scope. The purpose of this paper is to describe the task of acquiring emissions data in the construction domain, to highlight its complexity, and to establish a template for data collection. This paper constitutes a recommendation on how to do the field studies to collect the emissions data needed by the construction industry. With that data, the industry can then effectively manage its equipment and vehicle assets with responsible stewardship.

This paper presents a formal methodology for real-world emissions data collection from in-use construction vehicles. These procedures have been successfully applied for 54 tests to obtain emissions data from 39 separate construction vehicles. This data underwent a screening process and is considered to be of good quality. Furthermore, this data is available for analyses by other researchers.

Real-world emissions measurements allow for data analysis on many levels. For example, emissions data from construction vehicles can be analyzed and compared based on the type of vehicle that is used, the type of fuel that is used in the vehicle, the task that is being performed by the vehicle, and the individual activity modes of the vehicle. These results can be used to establish accurate emission factors and reliable emissions inventories for the construction industry.

This paper focuses on real-world measurements from eight types of construction vehicles. However, these procedures can be used to collect data from other types of construction vehicles that are used in the development of the nation's infrastructure, such as cranes, compactors, 
rollers, and scrapers. Furthermore, the data collection procedures presented here can be modified to collect real-world measurements from other types of nonroad diesel vehicles, particularly vehicles and equipment that are used in agriculture.

\section{ADDITIONAL WORK}

The real-world emissions data measurements presented here has served as the foundation for additional work evaluating the emissions and fuel use of construction vehicles. Abolhassani et al [2007] evaluated the real-world, in-use activity, fuel use, and emissions of excavators. Frey et al (1) [2008] performed a comparison of emissions from backhoes, front-end loaders, and motor graders performing real-world activities using petroleum diesel versus B20 biodiesel. Frey et al (1) [2008] also characterized the real-world activity, fuel use, and emissions of selected motor graders fueled with petroleum diesel and B20 biodiesel.

The work presented in this paper has also been used to assess emissions regulations, compare data sources, and evaluate fleet management decisions. Lewis et al (1) [2008] examined requirements and incentives for reducing emissions from construction vehicles and also advocated the use of real-world emissions data versus emissions data obtained from engine dynamometer tests. Lewis et al (2) [2008] also discussed the development and use of an emissions inventory for a fleet of backhoes, front-end loaders, and motor graders to make fleet management decisions related to replacing older vehicles with newer vehicles.

Although much work has been done related to emissions from construction vehicles, much more remains to be done. Areas of interest include data modeling to predict fuel use and emissions of construction vehicles, life cycle emissions of construction vehicles, and the impact of construction vehicles on greenhouse gas emissions. 


\section{ACKNOWLEDGEMENTS}

This material is based upon work supported by the National Science Foundation through Grant No. 0327731 and also by the North Carolina Department of Transportation through Research Project No. HWY - 2006 - 08. Any opinions, findings, and conclusions or recommendations expressed in this material are those of the authors and do not necessarily reflect the views of the NSF or the NCDOT.

\section{REFERENCES}

Abolhasani, S., C. Frey, K. Kim, S. Pang, W. Rasdorf, and P. Lewis, (2008). Real-World In-Use Activity, Fuel Use, and Emissions for Nonroad Construction Vehicles: A Case Study for Excavators, Journal of the Air \& Waste Management Association, Vol. 58, 1033 - 1046.

Battelle (2003). Environmental Technology Verification Report: Clean Air Technologies International, Inc. REMOTE On-Board Emissions Monitor, Prepared by Battelle for the U.S. Environmental Protection Agency, Columbus, $\mathrm{OH}$.

Bilec, M., R. Ries, H. Matthews, and A. Sharrard (2006). Example of a Hybrid Life-Cycle Assessment of Construction Processes, Journal of Infrastructure Systems, Vol. 12, No. 4, 207 $-215$.

California Air Resources Board (2004). "Rulemaking on the Proposed Amendments to the California Off-Road Emissions Regulation for Compression-Ignition Engines and Equipment," Amend Article 4, Chapter 9, Division 3, Title 13, California Code of Regulations (CCR).

CATI (2003). OEM-2100 Montana System Operation Manual, Clean Air Technologies International, Inc., Buffalo, New York.

CFR (2007). Title 40 - Protection of Environment, Part 50 - National Primary and Secondary Ambient Air Quality Standards, Code of Federal Regulations, Vol. 2, pp. 5 - 127. Available at www.access.gpo.gov/nara/cfr/waisidx_07/40cfr50_07.html.

ENR (2006). “Clean Up...or Clear Out,” Engineering News Record, McGraw-Hill, New York, NY. May 29, 2006, pp. 48 - 51.

EPA (1) (2005). User's Guide for the Final NONROAD2005 MODEL, EPA-420-R-05-013, U.S. Environmental Protection Agency, Ann Arbor, MI.

EPA (2) (2005). Clean Air Nonroad Diesel Rule Summary, EPA-420-F-04-029, U.S. Environmental Protection Agency, Ann Arbor, MI 2005.

EPA (2007). 1970 - 2006 Average Annual Emissions, All Criteria Pollutants, http://www.epa.gov/ttn/chief/trends/index.html.

Frey, C., (1) W. Rasdorf, K. Kim, S. Pang, P. Lewis, and S. Abolhassani (2007). "Real-World Duty Cycles and Utilization for Construction Equipment in North Carolina," Final Report for 
Research Project No. HWY - 2006 - 08, North Carolina Department of Transportation, Raleigh, NC.

Frey, C., (2) W. Rasdorf, K. Kim, S. Pang, P. Lewis, and S. Abolhassani (2007). "Life Cycle Inventory and Impact Analysis Framework for Nonroad Construction Vehicles and Equipment (TSE03-L),” Research Project for National Science Foundation, Arlington, Va.

Frey, C. (1), W. Rasdorf, K. Kim, S. Pang, and P. Lewis (2008). Comparison of Real World Emissions of Backhoes, Front-End Loaders, and Motor Graders for B20 Biodiesel vs. Petroleum Diesel and for Selected Engine Tiers, Transportation Research Record, Number 2058, 33 - 42.

Frey, C. (2), K. Kim, W. Rasdorf, S. Pang, and P. Lewis (2008). Characterization of Real-World Activity, Fuel Use, and Emissions of Selected Motor Graders Fueled with Petroleum Diesel and B20 Biodiesel, Journal of the Air \& Waste Management Association, (In Press).

Glaser, S. and A. Tolman (2008). Sense of Sensing: From Data to Informed Decisions for the Built Environment, Journal of Infrastructure Systems, Vol. 14, No. 1, 4 - 14.

Guggemos, A., and A. Horvath (2005). Comparison of Environmental Effects of Steel- and Concrete- Framed Buildings, Journal of Infrastructure Systems, Vol. 11, No. 2, 93 - 101.

Hildreth, J., M. Vorster, and J. Martinez (2005). Reduction of Short-Interval GPS Data for Construction Operations Analysis, Journal of Construction Engineering and Management, Vol. 131, No. 8, 920 - 927.

Junnila, S. and A. Horvath (2003). Life-Cycle Environmental Effects of an Office Building, Journal of Infrastructure Systems, Vol. 9, No. 4, 157 - 166.

Lewis, P. (1), W. Rasdorf, C. Frey, K. Kim, and S. Pang (2008). Requirements and Incentives for Reducing Construction Vehicle Emissions and Comparison of Nonroad Diesel Engine Emissions Data Sources, Journal of Construction Engineering and Management, Submitted.

Lewis, P. (2), C. Frey, and W. Rasdorf (2008). Development and Use of Emissions Inventories for Construction Vehicles, Transportation Research Record, Submitted.

Matthews, H., C. Hendrickson, and A. Horvath (2001). External Costs of Air Emissions from Transportation, Journal of Infrastructure Systems, Vol. 7, No. 1, 13 - 17.

Stephens, R. and S. Cadle (1991). Remote Sensing Measurements of Carbon Monoxide Emissions from On-Road Vehicles, Journal of Air \& Waste Management Association, Vol. 41, 39 - 46.

Zapata, P. and J. Gambatese (2005). Energy Consumption of Asphalt and Reinforced Concrete Pavement Materials and Construction, Journal of Infrastructure Systems, Vol. 11, No. 1, 9 20. 